(d) Diet deficiency in Vitamin A during pregnancy in experimental rats (Wilson \& Warkany, 1949.

The prognosis in congenital absence of one lung depends on the presence or absence of other associated congenital abnormalities, together with increased vulnerability to pulmonary infections.

\section{Acknowledgments}

I am grateful to $\mathrm{Mr}$ A. Logan, Consultant Thoracic Surgeon, The Royal Infirmary, Edinburgh, for permission and assistance to publish details of these two patients who were under his care in the Thoracic Unit.

\section{Referenc:es}

Burger, R.A. (1947) Agenesis of the lung. American Journal of Diseases of Children, 73, 481.

Butlek, N.R., Dudgeon, G.A., Hayes, K., Peckham, C.S. \& WYBAR, K. (1965) Persistence of rubella antibody with and without embryopathy. British Medical Journal, 2, 1027.

Campbell, M. (1961) Place of maternal rubella in the aetiology of congenital heart disease. Britısh Medical Journal, 1, 691.

Chaireaux, A.E. \& Ferreira, H.P. (1958) Bilateral pulmonary agenesis. Archives of Disease in Childhood, 33, 364.

FERENCZ, C. (1961) Congenital abnormalities of pulmonary vessels and their relation to malformation of the lung. Pediatrics, 28, 193.

FIELD, C.E. (1946) Pulmonary agenesis and hypoplasia. Archives of Disease in Childhood, 21, 61.

Finkelstein, H. (1912) Hypoplasie und agenesie der lunge. In Lehrbuch der Sauglings-Krankheiter. Fischer's medizin, Berlin.

ForRester, R.M., L.eFs, V.T. \& WATSON, G.H. (1966) Rubella syndrome: escape of a twin. British Medical Journal, 1, 1402.

HeErup, L. (1927) Et Tibfælde af venstresidig Lungemangel. Hospitalstidende, 70, 1165.

Jimenez-Martinez, M., Perez-Alvarez, J.J., Perez-Trevino, C., Rubio-Alvarez, V. \& De Rubens, J. (1965)
Agenesis of the lungs with patent ductus arteriosus treated surgically. Journal of Thoracic and Cardiovascular Surgery, 50, 59.

Killingsworth, W. \& Hibrs, W.G. (1939) Agenesis of the lung. American Journal of Diseases in Children, 58, 571.

Lucas, D.S., DotTer, C.T. \& Steinberg, I. (1953) Agenesis of the lung and patient ductus arteriosus with reversal of flow. New England Journal of Medicine, 249, 107.

LÜDIN, M. \& WERTHEMANN, A. (1930) Lungenveränderungen nach experimenteller Röntgenbestrahlung. Strahlentherapie, 38, 684.

MaIer, H.C. \& Gauld, W.J. (1953) Agenesis of the lung with vascular compression of tracheo-bronchial tree. Journal of Paediatrics, 43, 39.

MorgagNI, J.B. (1769) The seats and causes of diseases investigated by anatomy (Translated by B. Alexander) A. Miller, London.

Neill, C.A., Ferencz, C., Sabiston, D.C. \& Sheldon, H. (1960) The familial occurrence of hypoplastic right lung with systemic arterial supply and venous drainage. Bulletin of Johns Hopkins Hospital, 107, 1.

Nelson, C.S., McMillan, I.K.R. \& Bharucha, P.K. (1967) Tracheal stenosis, pulmonary agenesis and patent ductus ateriosus. Thorax, 22, 7.

Oyamada, A., Gasul, B.M. \& Holinger, R.H. (1953) Agenesis of the lung. American Journal of Diseases of Children, 85, 182.

Schмiт, H. (1893) Einfall von vollstandiger agencsiebeider Lungen. Virchow's Archives, 134, 25.

Schneider, P. \& Schwalbe, E. (1913) Die morphologie der missblidungen des menschen und der Tiere, 3, 763. Fisher, Jena.

Smart, J. (1946) Complete congenital agenesis of lung. Quarterly Journal of Medicine, 15, 125.

TUYNMAN, P.E. \& GARDNER, L.W. (1952) Bilateral aplasia of the lung. Archives of Pathology (Chicago), 54, 306.

Wexels, P. (1951) Agenesis of the lung. Thorax, 6, 171.

WILSON, J.G. \& WARKANY, J. (1949) Aortic arch and cardiac anomalies in the offspring of vitamin A deficient rats. American Journal of Anatoiny, 85, 113.

Yount, F. (1948) Agenesis of right lung in each of identical twins. Arizona Medicine, 5, 48.

\title{
Congenital abdominal coarctation with renal artery hypoplasia, hypertension and rheumatoid arthritis
}

\author{
N. NAGARATNAM* \\ M.D., M.R.C.P.(Glasg)
}

Physician

\author{
W. M. T. WeERASINGHE \\ M.B.B.S.(Cey)
}

House Physician

Government Hospital, Kegalle, Ceylon

STENOSING LESIONS of the abdominal aorta are rare. They are of varied aetiology, and may be due to congenital anomalies, atherosclerosis, dissecting aneurysm and acquired lesions of the inflammatory type of specific and of non-specific origin. Abdominal coarctation can occur above or below the level of the renal arteries. If the renal arteries are involved a syndrome of Goldblatt hypertension is produced.

* Present Address: Government Hospital, Gampaha, Ceylon
This paper reports a case of congenital abdominal coarctation with renal artery hypoplasia and hypertension associated with rheumatoid arthritis in a girl of 13 years.

\section{Case report}

A girl, aged 13 years was admitted on 17 April 1967 with a history of swelling of her joints of 3 years' duration, headache and effort dyspnoea of 1 years' duration. 
On examination, she was well nourished but mildly anaemic. There was low grade fever during her stay in hospital. No lymph glands were palpable. Clinically, her heart was not enlarged nor were there any murmurs heard. The blood pressure in her upper limbs was $240 / 140 \mathrm{mmHg}$ and in her lower $200 / 140 \mathrm{mmHg}$. Pulsations in all her peripheral arteries were equal, normal and there was no delay. A systolic murmur was heard over the abdomen anteriorly and in relation to her lumbar spine posteriorly. It was more pronounced on the right side. No collaterals were seen or felt. The lungs were clear. The spleen, liver and the kidneys were not palpable, nor were there any palpable lumps. The elbow joint was swollen, warm, tender and ankylosed at $45^{\circ}$. The right ankle joint was tender. There was spindling of the interphalangeal joints. No rheumatoid nodules were seen. Examination of the ocular fundi revealed a Grade I retinopathy.

Investigations: $\mathrm{Hb} 8.6 \mathrm{~g} \%$, PCV $35 \%$, WBC 12,000 cells $/ \mathrm{mm}^{3}$, $58 \%$ neutrophils, $28 \%$ lymphocytes, $12 \%$ eosinophils and $2 \%$ mononuclear cells. Serum bilirubin $0.2 \mathrm{mg} \%$, zinc sulphate turbidity 10 units, thymol turbidity 2 units, thymol flocculation nil, alkaline phosphatase $18.5 \mathrm{KA}$ units. Total proteins were $7.2 \mathrm{~g} \%$ and the A/G ratio was 1.01 , albumin $48.9 \%$, alpha-1 globulins $5.6 \%$, alpha-2 globulins $14.2 \%$, beta-globulins $8.5 \%$ and gamma-globulins $22.8 \%$. Anti-streptolysin ' $O$ ' titre 300 units. LE cells and latex flocculation tests negative, blood urea $20 \mathrm{mg} / 100 \mathrm{ml}$, serum sodium 130 potassium $4.7 \mathrm{mEq} / 1$. Urianalysis was unremarkable ECG: sinus rhythm, LVH. X-ray: cardiothoracic ratio of $11 / 20.5$ and a slightly enlarged and widened ascending aorta. There was no evidence of calcification. On fluoroscopy, there was no appreciable chamber enlargement. X-ray of the joints showed moderate rarefaction of both hands and elbow joints. IVP: satisfactory concentration of dye in both kidneys. The renal contour was smooth and there was no evidence of cortical scarring. The renal shadow was enlarged and the pelvicalyceal pattern was normal with slightly increased density of pelvicalyceal system on the left side. Transfemoral aortogram showed coarctation of the abdominal aorta just above the renal arteries (Fig. 1). The rest of the aorta and the great vessels were normal. The renal arteries appeared normal and there was no accessory vessels seen.

\section{Operation}

(Mr A. T. S. Paul). At the operation there was a coarctation of the abdominal aorta at the level of the renal arteries and involving the right renal artery. A systolic thrill was felt over the aorta; there was adequate blood flow and pulsation of the aorta distal to the coarctation. The right renal artery

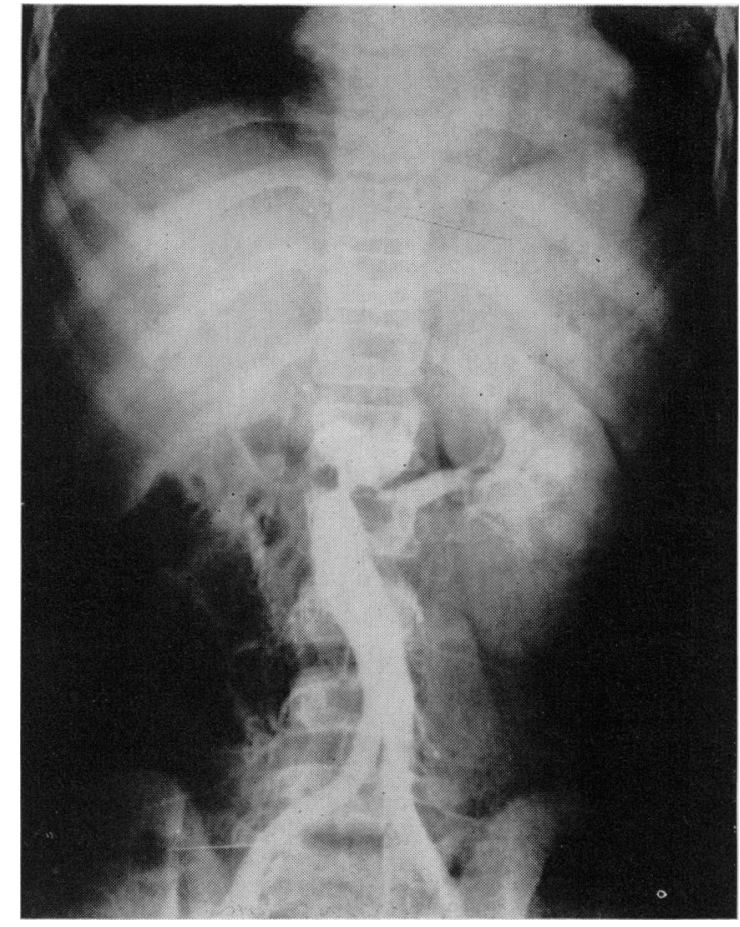

Fig. 1. Transfemoral aortogram to show the coarctation of the abdominal aorta just above the renal arteries.

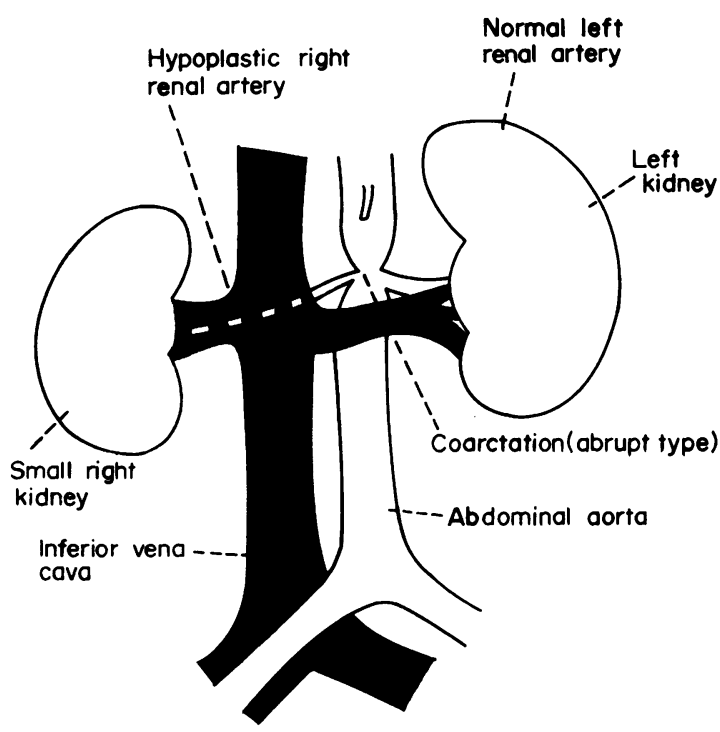

FIg. 2. Diagram showing findings at operation. Coarctation of the abdominal aorta at the level of the renal arteries with hypoplastic right renal artery and small right kidney. 
supplying a small kidney was hypoplastic and there was hardly any flow through it. The left renal artery has good pulsations and was not explored. There were no accessory vessels to the kidneys. As the right renal artery was too slender to graft, right nephrectomy was performed, but not resection of the coarctation. Post-operatively the patient made an uneventful recovery. The blood pressure dropped to $160 / 100 \mathrm{mmHg}$ soon after the operation and remained at this level for 3 days but gradually rose to $160 / 120 \mathrm{mmHg}$ by 19 October 1967 . She was given guanethidine $10 \mathrm{mg}$ daily from 27 October 1967 and her pressure was maintained at $150 / 100$ $\mathrm{mmHg}$.

Histology: The renal artery showed no inflammatory changes. The glomeruli and tubules were normal but an occasional atrophic glomerulus was seen and there was medial hypertrophy of the arteries.

\section{Discussion}

Kondo et al. (1950) described a case of true congenital coarctation of the abdominal aorta in a 12year-old girl with hypertensive heart failure. One of the cases described by Bahnson, Cooley \& Sloan (1949) appear to be of this type. Sen and his colleagues (1963) in their series of sixteen cases described under the heading of 'middle aortic syndrome', observed only four cases which they could call congenital. These included both supraand infradiaphragmatic lesions.

As stated earlier, occlusive disease of the aorta may be due to one of several pathological processes and the clinical picture may closely simulate that due to the congenital lesion. Besides arteriosclerosis, Takayasu's arteritis may involve the aorta. In this condition the thoracic aorta is involved together with the proximal segments of its large branches by a stenosing inflammatory process. The abdominal aorta and its branches are rarely affected independently of the rest of the arterial tree.

Danaraj \& Wong (1959) reported two fatal cases of primary arteritis of the abdominal aorta histologically resembling Takayasu's arteritis, where there was bilateral renal artery stenosis and hypertension. Subsequently, Danaraj and his colleagues (1963) described nine cases of primary arteritis of the aorta and in three of them the hypertension was established at necropsy as due to renal ischaemia consequent to stenosis of the orifices of one or both renal arteries. The clinical presentation in their series was of cardiac failure, encephalopathy of cerebral haemorrhage due to hypertension. In the series described by Sen et al. (1963) the presenting symptomatology was due to the hypertension, namely, cardiac failure, intracranial haemorrhage or headache or to occlusion of the aorta giving rise to intermittent claudication, abdominal angina and weak or absent pulses at the extremities. They were seen as in the cases described by Danaraj et al. (1963) in children and young female adults.

Choa, Rassim \& Wong (1963) described a case of thrombotic vascular disease of the abdominal aorta, the renal arteries and the subclavian artery in a young Chinese woman with malignant hypertension.

In this case no histopathological study of the aorta has been possible. The entire renal artery was hypopla'stic and its histology showed no inflammatory changes. Congenital coarctation is usually of the abrupt type giving rise to a localized stenosis as in our case and in those described by others (Kondo et al., 1950; Bahnson et al., 1949). Hence it is reasonable to assume that the obliterative lesion in our case is congenital. The associated arthritis was probably incidental and was of the rheumatoid type clinically, although there is no serological evidence of its rheumatoid aetiology. Stenotic lesions due to acquired causes give rise to an elongated narrowing, especially so when they occur in the mid-thoracic aorta. However, Milloy \& Fell (1959) described such a case of congenital coarctation involving the mid-thoracic aorta. Maycock (1937) suggested that congenital coarctation of the thoracic and abdominal aorta might be due to changes involving an unequal fusion of two dorsal aortas with obliteration and loss of one of them.

Patients with abdominal coarctation usually present with hypertension or its sequelae, intermittent claudication and absent or weak pulsations in the lower extremities. The only useful sign referable to the site of the coarctation is the presence of a bruit heard on the dorsum or anteriorly over the abdominal wall as in our case. Our patient presented with headache and effort dyspnoea. She had no intermittent claudication and her pulses were normal, equal and without delay in her lower extremities. In this patient in addition to the coarctation, the right renal artery was hypoplastic with greatly diminished flow through it.

\section{Acknowledgments}

We are indebted to Professor K. Rajasuriya for his help in many ways, to Dr W. L. S. Candappa who referred the case to us, to Dr Cuda Wijeyeratne for his advice in the preparation of this paper and to the Superintendent of Health Services, Kegalle for permission to publish.

\section{References}

Bahnson, H.T., Cooley, R N. \& Sloan, R.D. (1949) Coarctation of the aorta at unusual sites. American Heart Journal, 38, 905.

ChOA, G.H., Rassim, H.S. \& Wong, W.L. (1963) Thromboobliterative vascular disease of early onset and long duration. British Heart Journal, 25, 814. 
DanaraJ, T.J. \& WoNG, H.O. (1959) Primary arteritis of the abdominal aorta in children causing bilateral stenosis of the renal arteries and hypertension. Circulation, 20, 856.

DanaraJ, T.J., Wong, H.O. \& Thomas, M.A. (1963) Primary arteritis of the aorta causing renal artery stenosis and hypertension. British Heart Journal, 25, 153.

Kondo, B., Windsor, T., Raulston, B.O. \& Kuroiwa, D. (1950) Congenital coarctation of the abdominal aorta. A theoretically reversible type of cardiac disease. American Heart Journal, 39, 306.

MAYCOCK, W.D'A. (1937) Congenital stenosis of the abdominal aorta. American Heart Journal, 13, 633.

Milloy, F., \& Fell, E.H. (1959) Elongate coarctation of the aorta. Archives of Surgery, 78, 759.

Sen, P.K., Kinare, S.G., Engineer, S.D. \& Parulkar, G.B (1963) The middle aortic syndrome. British Heart Journal, 25, 610 .

\title{
A case of self-poisoning with Carbrital
}

\author{
JoHN COLLINS \\ B.D.S., M.B., M.R.C.P. \\ Registrar in Clinical Toxicology and Intensive Care, Guy's Hospital, \\ London, S.E.1
}

\section{Case Report}

A 67 year-old woman was admitted one-and-a-half hours after taking 50 capsules of Carbrital, each containing pentobarbitone sodium $100 \mathrm{mg}$ and carbromal $250 \mathrm{mg}$.

On admission she was comatose and areflexic except for the prese:vation of the cough reflex. The pulse was 72 /minute, sinus rhythm and tlood pressure $90 / 50 \mathrm{mmHg}$. There were no signs of cardiac or peripheral circulatory failure at this time.

In the accident and emergency department gastric lavage was performed with a wide-bore tube. An intravenous infusion was set up with $1 / 6$ molar sodium lactate solution and frusemide $20 \mathrm{mg}$ was given intravenously. The patient was then transferred to the Medical Intensive Care Unit for further treatment.

\section{First $24 \mathrm{hr}$}

For the first $24 \mathrm{hr}$ after admission an alkaline diuresis was produced using alternate $540 \mathrm{ml}$ bottles of $1 / 6$ molar sodium lactate solution and $5 \%$ dextrose solution. Potassium chloride $0.75 \mathrm{~g}$. (10 mEq.) was added to alternate bottles and the diuresis was maintained by intermittent intravenous frusemide, $380 \mathrm{mg}$ being administered in $24 \mathrm{hr}$. In addition the patient was given hydrocortisone $100 \mathrm{mg}$ intramuscularly 4-hourly and $35 \%$ oxygen by Ventimask.

A chest X-ray taken during this period showed a vaguely outlined radio-opaque mass in the left hypochondrium. It was suggested that this could possibly be the ingested capsules; subsequent events lent support to this suggestion.

Throughout this period the blood pressure never rose above $95 / 60 \mathrm{mmHg}$ and the rectal temperature was consistently below $94^{\circ} \mathrm{F}$ at one point. The patient remained deeply comatose but the cough reflex was preserved.

\section{Second $24 \mathrm{hr}$}

It was decided to abandon the alkaline diuresis and the intravenous infusion was continued at a slower rate with alternating bottles of normal saline and $5 \%$ dextrose with similar quantities of potassium chloride in alternate bottles.

After $40 \mathrm{hr}$ spontaneous respiration ceased and the patient developed atrial fibrillation. An endotracheal tube was passed and respirations were maintained using an East Radcliffe Positive Pressure Ventilator. Following this the patient reverted to sinus rhythm spontaneously.

$46 \mathrm{hr}$ after admission the patient suffered a cardiac arrest but was restored to sinus rhythm after a brief period of external cardiac massage and one DC countershock of 100 Joules.

\section{After $48 \mathrm{hr}$}

Following this episode of cardiac arrest no further cardiac dysrhythmias were noted and the level of consciousness slowly rose. At $74 \mathrm{hr}$ the endotracheal tube was removed and spontaneous respiration was restored. $90 \mathrm{hr}$ after admission the patient was sufficiently conscious to answer simple questions coherently and was then transferred to a general medical ward. The patient was referred to a Consultant Psychiatrist and was discharged 24 days after admission to receive outpatient treatment for depression.

\section{Findings}

In the first 24-hr $11,200 \mathrm{ml}$ of fluid were administered by intravenous infusion and 11 litres of urine were produced. The $\mathrm{pH}$ of each $500 \mathrm{ml}$ collected was shown to be greater than 8 .

During this period the plasma potassium was consistently low reaching $2 \cdot 3 \mathrm{mEq} / 1$ at one point. The plasma bicarbonate (auto-analyser) was raised 